Espacio, Tiempo y Forma, Serie VII, H. ${ }^{a}$ del Arte, t. 20-21, 2007-2008, págs. 37-55

\title{
Los ingenios de carpintería en la construcción del Monasterio de San Lorenzo el Real de El Escorial
}

\section{The carpentry devices in the construction of the Monastery of San Lorenzo el Real de El Escorial}

Manuel José García Sanguino*

RESUMEN

La considerable altura que fue alcanzando el Monasterio de San Lorenzo el Real de El Escorial requirió la construcción de grúas de madera para elevar del suelo los pesados bloques de granito gris de la Sierra de Guadarrama. Es en este preciso momento cuando algunos de los carpinteros, que trabajaban en tan insigne obra, pusieron al servicio de Felipe II su

audacia y habilidad técnica. El análisis exhaustivo y riguroso de la documentación existente en la biblioteca del Monasterio de San Lorenzo de El Escorial, esclarece la autoría de la fabricación de estas máquinas o ingenios.

\section{ABSTRACT}

The considerable height that the Monastery of San Lorenzo el Real de El Escorial was reaching, required the construction of wooden cranes to raise the heavy blocks of grey granite from the Guadarrama mountains. At that precise moment, some of the carpenters who were working on this notable construction, offered their courage and skills to Felipe II. The rigorous and comprehensive analysis of the existing documentation at the Royal Library in the Monastery clarifies who was responsible for the construction of those machines or devices.

\footnotetext{
* Doctor en Historia del Arte. UNED. E-mail: manueljosegarciasanguino@edu.ucm.es
} 


\section{PALABRAS CLAVE}

Felipe II, Monasterio de San Lorenzo el Real de El Escorial, ingenios de carpintería, Juan Bautista de Toledo, Juan de Herrera, "Architectura y Máchinas», Francisco Lobato, Pedro Juan de Lastanosa, Juan de Betesolo, Diego de Valmaseda, grúas, Juan de la Laguna, Julián Martínez, Juan Rojo, Pedro Flores.

\section{KEY WORDS}

Felipe II, Monastery of San Lorenzo el Real de El Escorial, carpentry devices, Juan Bautista de Toledo, Juan de Herrera, "Architectura y Máchinas», Francisco Lobato, Pedro Juan de Lastanosa, Juan de Betesolo, Diego de Valmaseda, cranes, Juan de la Laguna, Julián Martínez, Juan Rojo, Pedro Flores.

\section{INTRODUCCIÓN.}

El arquitecto e ingeniero Juan Bautista de Toledo ${ }^{1}$, después de su formación en Italia, representó la introducción en España un nuevo tipo de profesional humanista, superando los modelos de arquitectos e ingenieros de formación práctica gremial$^{2}$. Juan de Herrera, una vez que sucedió en el cargo a Juan Bautista, como arquitecto mayor de las obras del Monasterio de San Lorenzo el Real de El Escorial, destacó también por su labor en ingeniería ${ }^{3}$, relacionando los conceptos arquitectónicos con los ingenieriles, en un tema tan utilizado como son las grúas que se emplearon en la edificación de tan magna obra.

En el Archivo General de Simancas se conserva un documento titulado «Architectura y Máchinas» con el nombre de Juan de Herrera en la cubierta ${ }^{4}$. El título del libro es muy sugestivo ya que se centra en el principio matriz de las grúas que se emplearon en el Monasterio de San Lorenzo el Real de El Escorial. Se desconoce la fecha en que fue escrito el manuscrito, pero para los expertos en Juan de Herrera lo datan entre 1567 y 1577 que son los años de construcción de la mayor parte de las grúas del Monasterio ${ }^{5}$. La aportación de Juan de Herrera con su ma-

\footnotetext{
1 Juan Bautista de Toledo, hasta su muerte acaecida en 1567, precedió en el cargo a Juan de Herrera en la obra arquitectónica del Monasterio de San Lorenzo de El Escorial.

${ }^{2}$ RIVERA BLANCO, J. J., Juan Bautista de Toledo y Felipe II. Universidad de Valladolid, Secretariado de Publicaciones, 1984.

${ }^{3}$ La historia del ingeniero profesional, tal y como hoy la entendemos, ha estado ligada hasta el siglo pasado con la del arquitecto, siendo en algunos casos difícil de establecer tal distinción.

${ }^{4}$ Archivo General de Simancas (A.G.S.), Casas y Sitios Reales (C. y S. R), leg. 258, fol. 488. El manuscrito fue reproducido sin comentarios por AGUSTÍN RUIZ DE ARCAUTE, Juan de Herrera arquitecto de Felipe II, Madrid, Espasa-Calpe, 1936, págs. 36-38 y por EDISON SIMONS y ROBERTO GODOY: Discurso del señor JuanHerrera, aposentador mayor de S. M., sobre la figura cúbica. Madrid, Editora Nacional, 1976, págs. 169-174.

${ }^{5}$ Una posible fuente de inspiración para el manuscrito de Juan de Herrera «Architectura y Máchinas» fue el tratado de arquitectura de MARCO VITRUVIO POLIÓN: Los diez libros de arquitectura. Esta obra preparó ideológicamente el terreno para los grandes programas constructivos de la Roma imperial.
} 
nuscrito y la inventiva de algunos de los carpinteros que trabajaron en el Monasterio, fue determinante en la construcción de grúas para elevar del suelo los pesados bloques de piedra.

\section{CÓMO ERAN LAS GRÚAS QUE SE USARON EN EL MONASTERIO DE SAN LORENZO DE EL ESCORIAL.}

Las grúas que se usaron en la construcción de la Octava Maravilla del Mundo, se componían de dos partes esenciales: el elemento motriz, formado por un hombre o varios que giraban dentro de una o dos ruedas, y el mecanismo de elevación compuesto por una estructura que sustentaba un juego de tornos, poleas y cables cuya misión era el desplazamiento vertical de la carga. El único al que hace referencia Herrera en su manuscrito es el motriz, no hablando para nada del resto.

El conjunto motriz formado por hombres girando dentro de una rueda con objeto de mover una máquina, es muy anterior a las grúas del Monasterio. Este recurso técnico no sólo fue empleado en las grúas, sino en los más diversos artificios. El testimonio más antiguo que se tiene y famoso es el representado en el relieve del mausoleo de los Aterii en la Antigua Roma y que se conserva en el Museo de las Termas: varios esclavos introducidos en el interior de una gran rueda que gira, accionan a través de ella una serie de poleas sujetas a un alto mástil, con objeto de subir los elementos de construcción de un edificio. Este tipo de mecanismos se multiplicaron en la Edad Media y aparecen, por ejemplo, en las grandes grúas existentes en los puertos de los Países Bajos, de los que se conservan algunos grabados.

En el Renacimiento eran ya corrientes, es el caso de un personaje de Medina del Campo llamado Francisco Lobato, que en un manuscrito, reproduce una serie de máquinas de su época, sobre todo molinos, algunos de los cuales son de su propia invención. Uno de ellos representa lo que él denomina un «Molino de grúa que muele con un hombre» (fig. 1). Con un personaje dentro de una gran rueda en la que no falta ni la puerta para entrar en el interior. El manuscrito pertenece a los años 1577-1578, por lo que resulta ser contemporáneo de la construcción del Monasterio de San Lorenzo de El Escorial e indica que tal tipo de grúas eran corrientes para las obras de los edificios. La descripción más completa de una grúa contemporánea a las del Monasterio, es la contenida en el manuscrito conocido como Los veintiún libros de los ingenios y de las máquinas ${ }^{6}$, cuya autoría corres-

Los libros y bienes que poseyó Juan de Herrera, fueron inventariados y está reproducido en el libro de Agustín Ruiz de Arcaute ya citado y estudiada la biblioteca por LUIS CERVERA VERA: Inventario de los bienes de Juan de Herrera, Valencia, Albatros, 1977. 


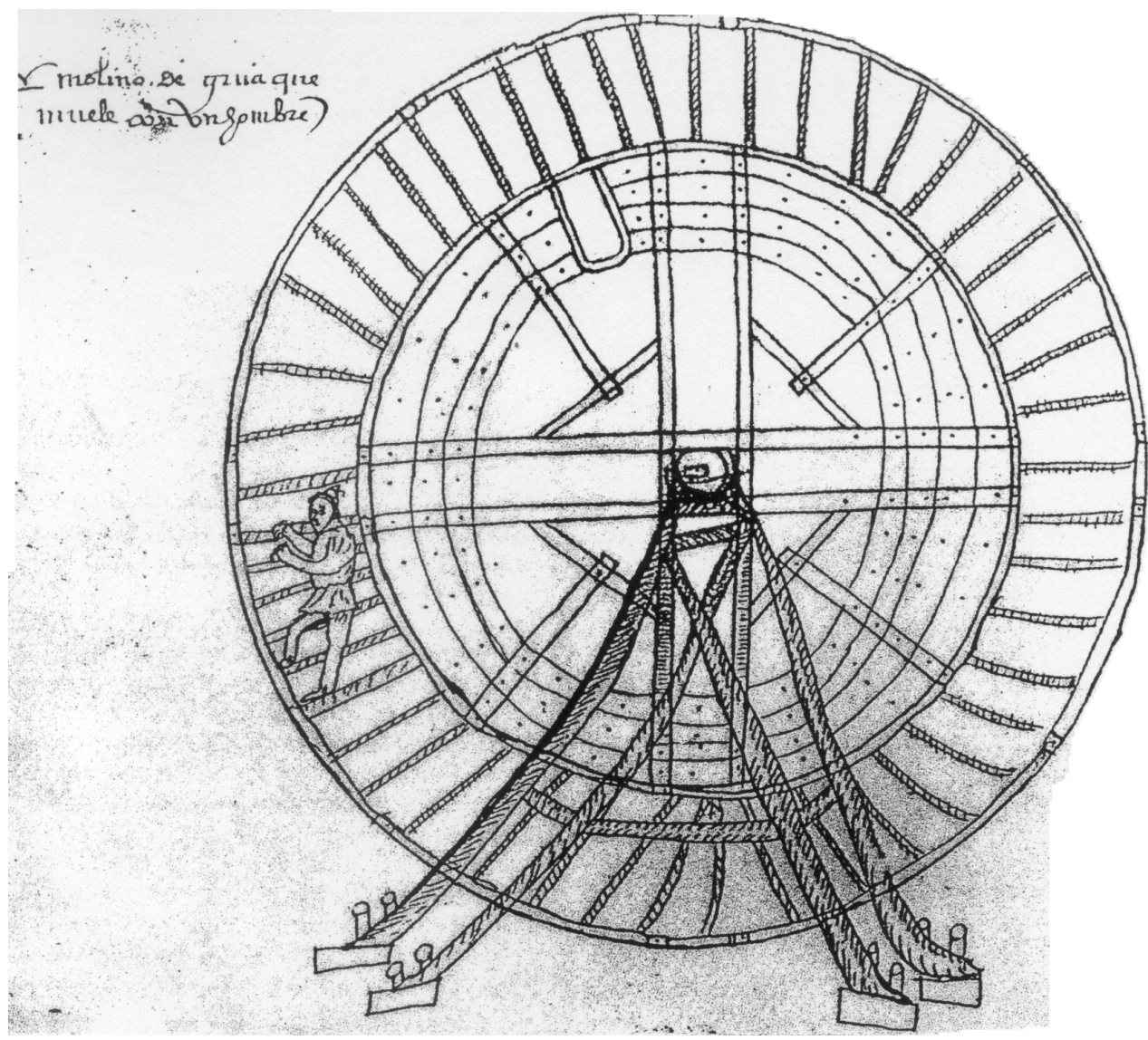

Fig. 1. Francisco Lobato. «Molino de grúa», según manuscrito del autor (c. 1577). Colección privada.

ponde a Pedro Juan de Lastanosa (1527-1576), un eminente aunque lamentablemente desconocido ingeniero teórico aragonés que lo escribiría hacia 1570 aproximadamente ${ }^{7}$. En la figura 2 se reproduce la grúa, con una explicación muy detallada:

${ }^{6}$ En un primer momento se pensó, hasta su publicación en 1983, que era del ingeniero de origen cremonés Juanelo Turriano, autor de relojes para Carlos I y Felipe II y del famoso artificio toledano de elevación de agua al Alcázar.

${ }^{7}$ El manuscrito, del siglo XVII, que se encuentra en la Biblioteca Nacional es copia del original perdido. Editado como «Pseudo-Juanelo Turriano», Los veintiún libros de los ingenios y de las máquinas. Madrid, Colegio de ingenieros de caminos, canales y puertos, 1983. Prólogo de José Antonio García-Diego demostrando la imposibilidad de su atribución a Turriano. 


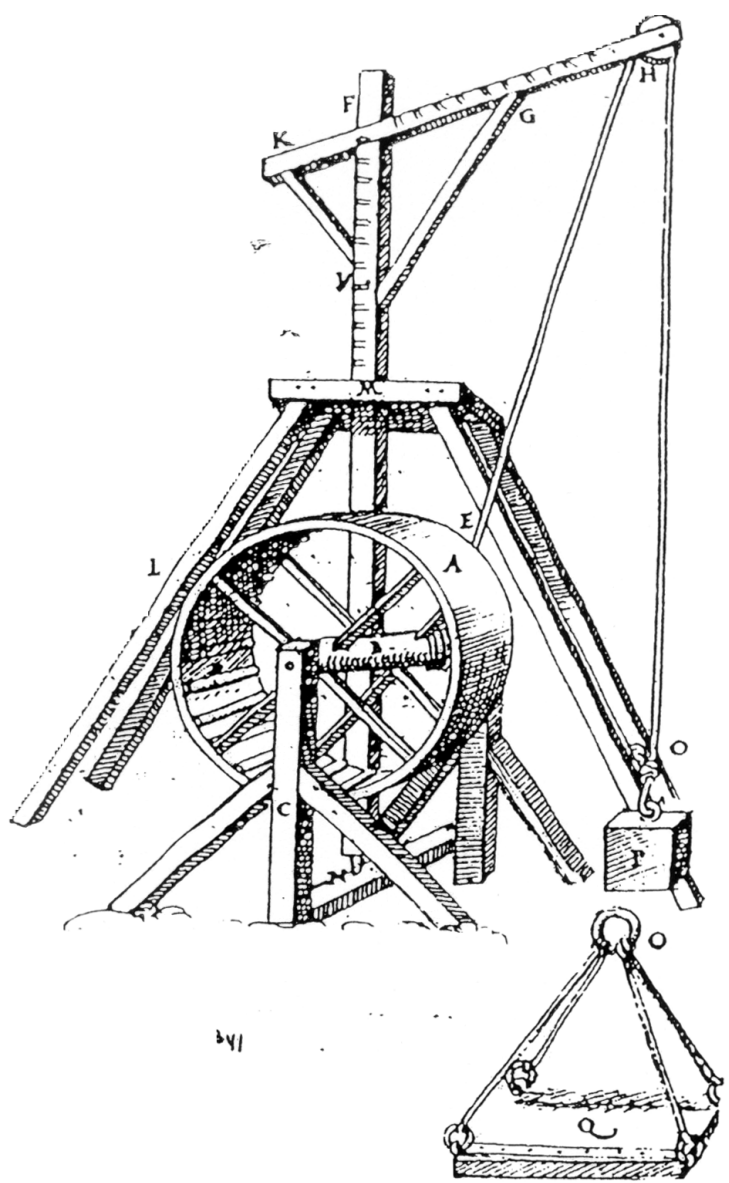

Fig. 2. Pedro Juan de Lastanosa. Grúa usada en edificación en la segunda mitad del s. xVI. Según "Los veintiún libros de los ingenios y de las máquinas" (c. 1570). Biblioteca Nacional. Madrid.

«La grúa es un instrumento de madera, el cual sube en alto las piedras de las obras. Es de sí muy alto, está asentado bajo en el suelo del edificio y otras veces se acomoda en alto según la necesidad del lugar. Subénse muy grandes pesos con la grúa y llévose con ella cualquier parte de la obra, sin ningún trabajo, por causa de que el árbol o mástil juega sobre un perne de hierro en $\mathrm{N}$. La rueda $\mathrm{A}$, que su eje es $B$, el cual juega a los dos cabos sobre los dos pies, es $C$ y este eje recoje la cuerda de la grúa que es $\mathrm{E}$, la cual pasa por la garrucha $\mathrm{H}$. La grúa así se llama por el largo cuello que saca el madero $\mathrm{K}$ que tiene la garrucha $\mathrm{H}$ y tiene aquellos dos rebotantes $\mathrm{G}$ que la sustentan y hay puestas unas clavijas de madera algo larga que sirven de escalones, y la armadura $\mathrm{M}$ tiene derecho el pie del árbol $\mathrm{F} . . .{ }^{8}$.

${ }^{8}$ Pseudo-Juanelo Turriano, Op. cit., pág. 516. 


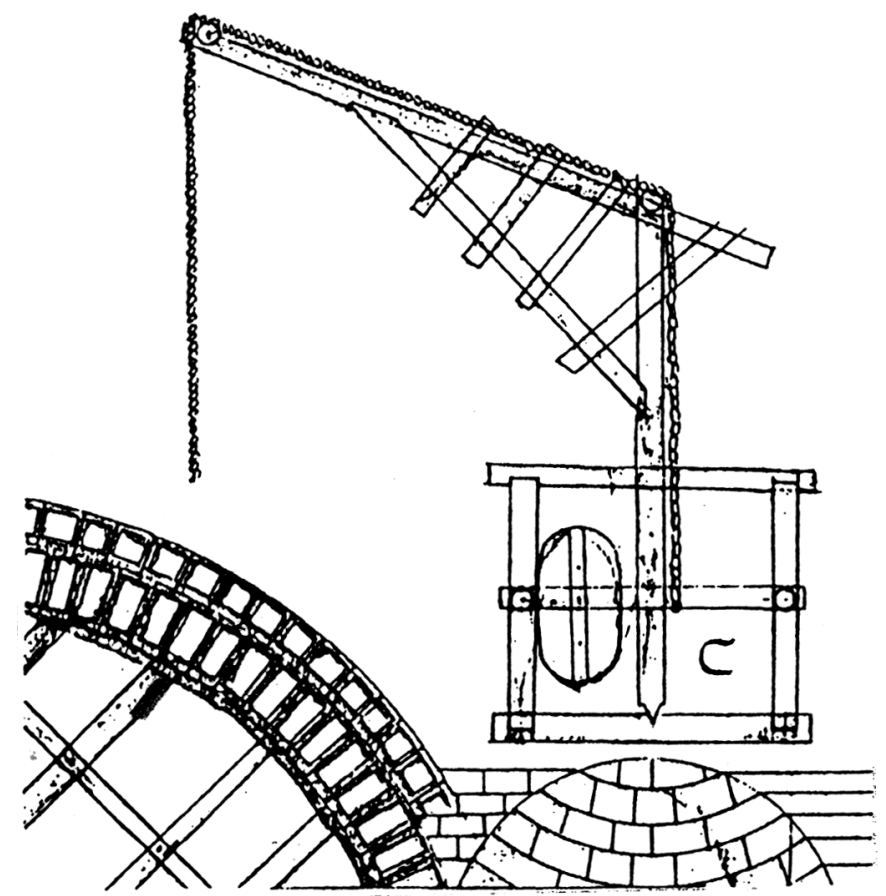

Fig. 3. Grúa usada en el puente de Zuazo en 1592. Archivo General de Simancas.

Salvo algunas variantes, esta sería el tipo de grúa utilizada en la construcción del Monasterio de San Lorenzo de El Escorial. Este tipo de grúa no fue algo novedoso, más bien todo lo contrario, pues venía ya funcionando en España hacía algún tiempo, como muestra la siguiente descripción de las condiciones para construir un guindaste en la obra del palacio de Carlos V en Granada en 1545:

«... había de hacerse como el que está hecho en la casa real con que agora se suben los materiales y piezas a la dicha obra con que se sirve excepto que la que se hiciere ha de ser la rueda algo mayor y el mástil ha de ser de dos piezas juntadas muy bien y galabernadas la una con la otra con sus buenos ceños de hierro y clavijas, por manera que esté muy fuerte y firme como si fuera de una pieza...»⿳9.

Este documento confirma que existen los mismos elementos que en las grúas que estamos examinando: la rueda, el mástil y la pluma o brazo. Asimismo, con fe-

${ }^{9}$ GÓMEZ MORENO, M., Las águilas del Renacimiento español. Madrid, C.S.I.C., Instituto Diego Velázquez (1941), 1983, apéndice XXVII, pág. 215. Documento, hoy perdido, procedente del Archivo de la Alhambra, leg. 228. 


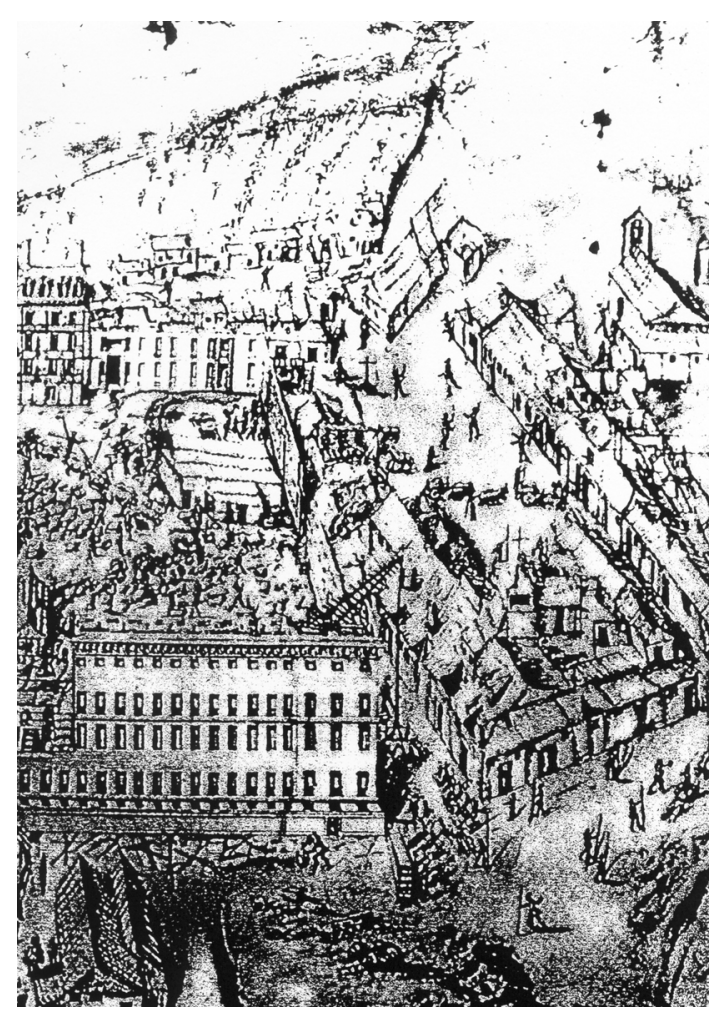

Fig. 4. Anónimo. Métodos constructivos en el Monasterio de San Lorenzo el Real de El Escorial. Dibujo perspectivo de la Colección Hatfield House.

cha algo posterior a la construcción del Monasterio de San Lorenzo el Real, 1592 para ser exactos, se seguía utilizando el mismo tipo de grúa como lo demuestra la figura 3, que procede de un detalle de la construcción del puente de Zuazo en Cádiz, reflejada en un plano del Archivo de Simancas ${ }^{10}$.

Además de todo ello, se conserva un dibujo de la Colección Hatfield House que reproduce una de las fases de construcción del propio Monasterio, en el que se detallan las grúas que en ella se emplearon (fig. 4). Todas estas máquinas se hacían de estructura de madera, excepto un elemento no funcional que aparece en los dibujos de Hatfield, y es la cruz que corona la pluma de todas las grúas. Esta cruz, representa la salvación de la máquina, implorando la protección divina de los que con ella trabajan. Las grúas giran y elevan al mismo tiempo su plegaria al cielo a través de esta cruz que la corona, igual que si se tratase de un campanario de igle-

\footnotetext{
${ }^{10}$ A.G.S., Mapas, Planos y Dibujos (M. P. y D.), VIII-68.
} 
sia o de los próximos chapiteles de las torres de las esquinas del mismo edificio del Monasterio. Este detalle no aparece en ninguna otra máquina de la época. Estas máquinas tan grandes manejando pesos tan elevados y sin grandes medidas de seguridad no tenían, por ejemplo, mecanismo para la detención de la grúa en caso de emergencia, provocaban numerosos accidentes que requerían la protección divina para estos hombres. Noticias de algunos accidentes han llegado hasta nosotros a través de los cronistas oficiales del Monasterio de San Lorenzo el Real, como los jerónimos fray Antonio de Villacastín y fray Juan de San Jerónimo. Así, en enero de 1580, el carpintero Andrés González, suplicaba a Su Majestad una limosna ya que en septiembre de 1569 se cayó, junto con otro carpintero, de una grúa de sesenta pies de alto (unos 17 metros) quedando lisiado, aunque el padre fray Antonio de Villacastín, obrero mayor del Monasterio de San Lorenzo de El Escorial, afirma en el mismo documento que su caída no fue desde tanta altura ${ }^{11}$. La crónica de fray Juan de San Jerónimo, narra un suceso ocurrido el 5 de julio de 1578. Parece ser que cuando se subía una piedra con una grúa, junto a la torre de las campanas, se soltó matando a un hombre que pasaba en ese momento por ahí.

«En cinco de Jullio del dho año de 1578 subiendo una pieca de piedra con una grua junto a la torre de las campanas de la parte del norte passando por debaxo un hombre cayo la piedra y le mato, que fue cosa de gran lastima y lo que fue de dolor es que este hombre echando a huir de la gran piedra se fue corriendo ameter debaxo de ella»12.

Si bien las grúas del Monasterio de San Lorenzo de El Escorial no representaron en sí mismas ninguna innovación tecnológica, eran de un tamaño inusual y su construcción requería, más que de la inteligencia y de los conocimientos matemáticos de un arquitecto, de la audacia y la habilidad de un especialista en estructuras de madera. Es en este momento, en el que la figura del carpintero se ve especialmente reforzada para solucionar los complejos problemas de las estructuras de los andamios y de las grúas.

\section{HISTORIA DE LA CONSTRUCCIÓN DE LAS GRÚAS DEL MONASTERIO DE SAN LORENZO DE EL ESCORIAL.}

El 10 de agosto de 1563, Felipe II dio unas instrucciones precisas de cómo se seguiría la fábrica. Uno de los aspectos más importantes de su contenido es la

${ }^{11}$ A.G.S., C. y S. R., leg. 261, fol. 192.

12 SAN JERÓNIMO, fr. Juan de., «Memorias», fol. 109v-110. Memorias de fray Juan de San Jerónimo. Madrid, Patrimonio Nacional, 1984. Reproducción facsímil de la edición publicada originalmente en colección de documentos inéditos para la Historia de España, vol. 7, por Miguel Salvá y Pedro Sáinz de Baranda. Madrid, Viuda de Galero, 1845. 
creación de la llamada congregación, organismo que estuvo integrado por el prior, vicario, contador y pagador. Además se crearon tres puestos de aparejadores especializados en un tipo distinto de obra: de cantería, que correspondió a Pedro de Tolosa y Lucas de Escalante; de albañilería desempeñado por Antón Ruiz, y de carpintería, para el que García de Quesada fue nombrado. Los aparejadores eran los delegados de los maestros mayores en la ejecución de las obras. El maestro mayor traza y supervisa. El aparejador está a pie de obra, vigilando los contratos. El papel supremo director de una obra real es el rey. En 1572 desapareció el cargo de maestro mayor y Juan de Herrera dependía, desde este instante, directamente de Felipe II. Durante los años en que se construyó el Monasterio de San Lorenzo el Real, la congregación tuvo bastantes problemas y conflictos con los distintos oficios que trabajaron en el Monasterio, entre ellos el de carpintería-ebanistería.

En algunos documentos de los primeros años de la década de los 70 , en los que aparecen las condiciones dadas a los carpinteros para que hiciesen los correspondientes destajos, se dice que se obliga a contratar «los peones, oficiales yngenios o tiros todo lo haga a su costa dándole los materiales para ello... ${ }^{13}$ Eran unos ingenios de pequeño tamaño que resolvieron temporalmente el problema de elevación de los grandes bloques de piedra. A medida que fueron alcanzando una mayor altura se necesitó la construcción de grúas. Se ha venido diciendo que la autoría de las grúas del Monasterio se debe al arquitecto Juan de Herrera y al carpintero Juan de Betesolo. Sin embargo, una vez revisada la documentación existente en el Archivo de la Real Biblioteca del Monasterio de San Lorenzo de El Escorial demuestra, en su auténtica medida, la contribución de numerosos especialistas que trabajaron en él.

Hay que distinguir dos fases claramente diferenciadas. La primera, que comprendería los primeros años constructivos de la insigne obra filipense, en la que no había necesidad de altas grúas, por lo que la carga y descarga de materiales se solucionaba con un simple aparato, «la cabrilla o cabrita», que consistió en un simple polipasto montado sobre un trípode ya utilizado por los romanos, descrito por Vitruvio y otros tratadistas de maquinaria renacentista (fig. 5). Sin embargo pronto este aparato empezó a ser insuficiente, como lo demuestra un documento existente en el Archivo General de Simancas dirigido por Andrés Almaguer al Rey, fechado el 13 de septiembre de 1563, el cual dice lo siguiente:

«Juan Bautista de Toledo dice que él dará otros ingenios más útiles para cargar las piedras en las carretas pero si $\mathrm{V}$. Magd. Manda que se pruebe, no se perderá nada, mayormente que don Juan Manrique me ha dicho que será muy útil este ins-

${ }^{13}$ Archivo Biblioteca de San Lorenzo de El Escorial (A.B.S.L.E.), III-63-1574; IV-1-574. 


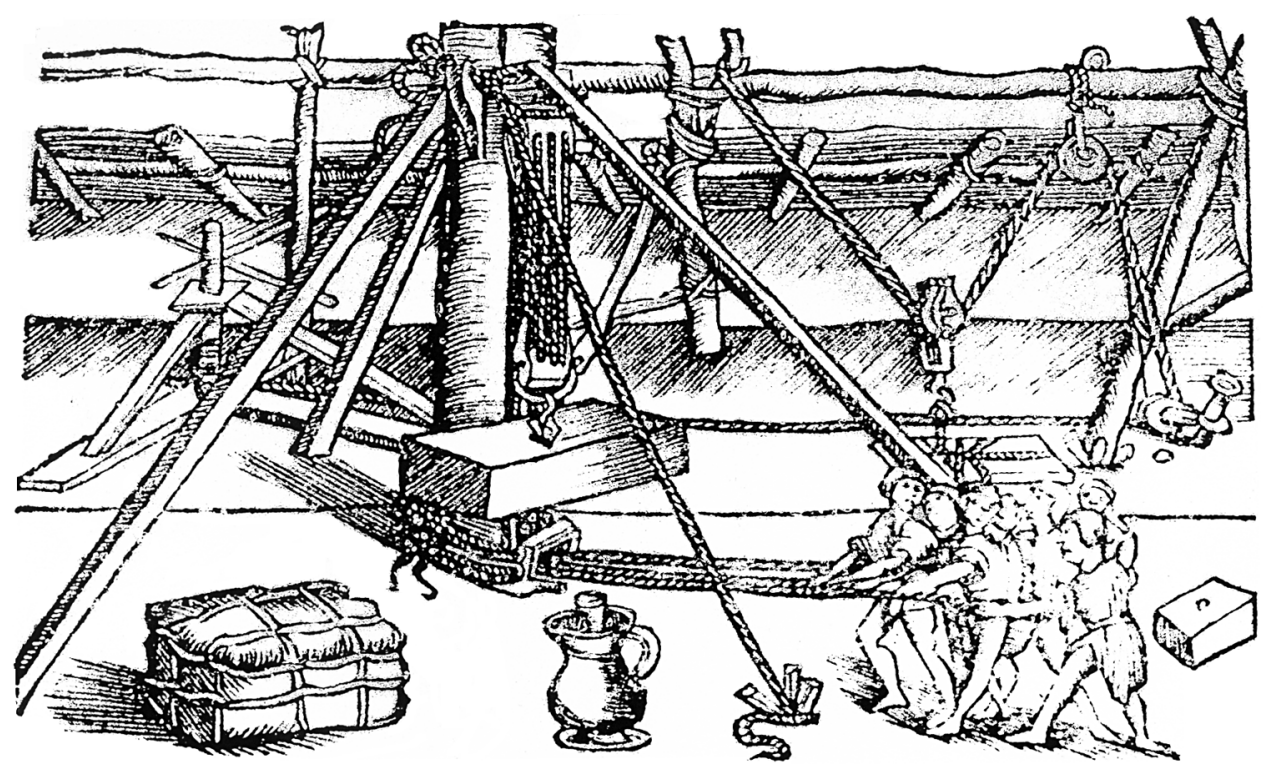

Fig. 5. Vitrubio. Grabado mostrando un ingenio para la elevación de sillares de piedra. Edición de Argentorati. 1550. Biblioteca del Monasterio de San Lorenzo el Real de El Escorial.

trumento para este uso y el del soldado de la guardia alemana [Juan de Herrera] de V. Magd. Para subir las piedras, que a su tiempo se puede probar».

Al margen contesta Felipe II: «No creo que se perderá nada en proballo»14.

De este documento se deduce que, en estos primeros años de construcción del Monasterio, cuando los muros empezaron a alcanzar una altura considerable y, por ello, se requirió la utilización de grúas, surgieron dos proyectos de ingenios para elevar las piedras de sillería: uno por el primer arquitecto del Monasterio, Juan Bautista de Toledo y, el otro, por el soldado de la guardia alemana Juan de Herrera, en ese momento ayudante de Juan Bautista. Pero estos ingenios no se habían construido aún varios años después, porque en un documento también de Almaguer dirigido a su «Magestad» y con fecha del 22 de febrero de 1566, se dice lo siguiente:

«En esta fábrica hay tanta falta de ingenio o instrumento para subir en alto las piezas que es lástima ver el trabajo, gasto y peligro que se pasa cuando se sube al-

14 í̃̃IGUEZ ALMECH, Fr., Los ingenios de Juan de Herrera. El Escorial 1563-1963. IV Centenario de la Fundación del Monasterio de San Lorenzo el Real, II, Arquitectura, Artes, Madrid, 1963, pág. 194. El documento original en A.G.S., C. y S. R., leg. 260, fol. 247. 
guna [pieza] y como [ni] el maestro mayor ni los aparejadores no lo proveen, ha salido uno de los destajeros que hará un ingenio, con que trigan las piezas y suben la mayor con él cuatro hombres quince pies en alto y no costará más de veinte ducados poco más o menos y que si no fuere tal y como él ha dicho, que pierda su trabajo. V. m. Io trata con Su Magd. Y dándonos licencia le cometeremos que haga este ingenio».

Al margen escribe Felipe II:

«Que lo haga mucho norabuena y sino fuese tal, será menester apretar a Juan Bautista que los haga y en esto creo yo que será bueno ocupar a Herrera, que creo que lo entiende bien ${ }^{15}$.

Pocos meses después Almaguer vuelve a insistir en la falta de instrumentos y en lo que cuesta subir las piedras. El documento está fechado el 24 de julio de 1566. En él añade:

«Hartas veces se ha dicho esto a Juan Bautista y él dice que hará maravillas. Ternía por acertado que fuese Herrera o Tolosa y sacasen en limpio lo de estos ingenios. O se hiciesen por otra mano».

Felipe II responde en el mismo documento:

«Juan Bautista nunca acabará y será entorpecelle por lo que allá hace y Tolosa dice que él los hará buenos. Y así lo mejor será que escribáis luego que ordenéis a Tolosa que haga los que él hubiere menester y por los destajos. Y a Escalante lo mismo por lo que es a su cargo y si él no lo hiciese, se ayudaría de Juan Bautista o de Herrera, al cual me acordad que preguntemos después acá de qué manera podrá hacer alguno bueno» ${ }^{16}$.

En estos años Juan Bautista de Toledo estaba ya débil y agobiado de trabajo y Herrera no poseía todavía la formación suficiente. Además a esto hay que añadir que la muerte prematura de Juan Bautista de Toledo al año siguiente, en 1567, trajo un cierto desconcierto en las obras, hasta la toma de dirección de Herrera que organizó el trabajo del Monasterio, ordenando la labra de las piezas en la cantera y la adjudicación de la obra por el sistema de destajos, con el fin de agilizar y acelerar el trabajo.

En 1570, Diego de Valmaseda entró a trabajar como carpintero en la obra escurialense. Este carpintero, natural de Toledo, trabajó en la reparación y construcción de algunas de las grúas como así lo demuestra su intervención en la bi-

${ }^{15}$ A.G.S., C. y S. R., leg. 260, fol. 383.

16 Ídem., ídem., fol. 394. 
blioteca y el zaguán, ubicados en la fachada occidental del Monasterio, que tuvieron una intervención exhaustiva en 1572. El 14 de julio Pedro de Tolosa, aparejador de cantería, concertó con los canteros Peña y Dehesa la cornisa de las dos dependencias citadas. La grúa usada en el destajo se quebró al bajar una piedra, arreglándola el carpintero Diego de Valmaseda ${ }^{17}$. El citado carpintero construyó una grúa en el claustro mayor para el destajo de los canteros Baltasar de Arquiza, Juan Ezquerra, Pedro de Pasamar, Domingo Ortiz y Sebastián de Cabanco. La grúa la hizo por 60 ducados $^{18}$.

En 1576, la panorámica que ofrecía el Monasterio fue de una actividad y de un despliegue de medios digno de tan insigne edificio actuándose, por primera vez, al mismo tiempo, en todas las partes del mismo.

La impresionante altura, que progresivamente fueron alcanzando la fachada principal y la fachada de la basilica, obligó a contratar los servicios del maestro de carpintería Juan de la Laguna ${ }^{19}$ para que construyera grúas y andamios. En 1577 entró a formar parte de la nómina de carpinteros de la obra escurialense. Juan de la Laguna se especializó, como anteriormente lo había hecho Diego de Valmaseda, en la fabricación de estos complicados ingenios. Este nuevo rumbo que tomaron las obras de carpintería del Monasterio, en lo que a la fabricación masiva de grúas y andamios se refiere, originó la creación de nuevos puestos de trabajo.

En 1577 se inició una frenética labor en la construcción de la basílica. En esta fecha, Juan de la Laguna, hizo una grúa para la partida que los canteros Juan de Soria y Francisco Fernández, tenían en la iglesia principal, por la que se le pagó cuatrocientos cincuenta reales ${ }^{20}$. En mayo Juan de la Laguna recibió pagos por una grúa que hizo para la partida, que los canteros Francisco del Río y Diego de Cisniega, tenían en una de las dos torres campanario de la fachada de la basílica ${ }^{21}$. Los citados canteros tenían otra partida junto al pórtico de entrada de la iglesia. Juan de la Laguna hizo una grúa la cual se cayó por lo que tuvo que hacer una nueva, recibiendo 39 ducados $^{22}$. Juan de la Laguna continuó su incipiente labor ha-

${ }_{17}$ A.B.S.L.E., II-164-1572; III-2-1572. El 24 de diciembre de 1572, recibió cuatrocientos cuarenta reales por una grúa «que aderezó en el cuarto de la librería». Diego de Valmaseda colaboró con otros carpinteros, como Antonio de Cervantes y Pedro de Zamora, para hacer la carpintería de otras dependencias del Monasterio.

${ }^{18}$ A.B.S.L.E., III-24-1572.

${ }^{19}$ La única información que se tiene de este carpintero es que era vecino de San Miguel de Aras, en la Junta de Boto, Merindad de Trasmiera, tal y como aparece en los documentos. No sólo se dedicó a hacer grúas y andamios, también intervino en la capintería de otras dependencias del Monasterio formando compañía con otros profesionales de la madera entre ellos Pedro Mayor, Juan de Betesolo y Julián Rodríguez.

${ }^{20}$ A.B.S.L.E., VI-2-1577.

21 Ídem.

22 Ídem. 
ciendo una grúa para el destajo que los canteros, Francisco de Carranza y Juan de la Puente, tenían en la iglesia principal. Recibiendo, a finales de 1577, las correspondientes libranzas ${ }^{23}$. Juan de la Laguna culmina su labor en esta zona del Monasterio, haciendo dos grúas para los canteros Nicolás de Rivero y Juan de Matienzo ${ }^{24}$. Juan de la Laguna hizo, en 1577 , un total de seis grúas convirtiéndose en el pionero de una generación de carpinteros dedicados, en estos últimos años de la década de los 70 , en la imperiosa y necesaria construcción de grúas. La importante labor realizada por Juan de la Laguna, en lo que a construcción de grúas se refiere, se prolongó hasta principios de la década de los 80.

En esta trepidante actividad, llevada a cabo en el interior de la basílica, fue contratado el carpintero Pedro Valgado del que se desconoce su procedencia. El 1 de octubre de 1578, recibió pagos por haber desarmado una grúa y volverla a montar, en la partida de los canteros Juan de Soria y Francisco González ${ }^{25}$.

Los aposentos oficiales de Felipe II y su esposa Ana María, tuvieron gran actividad entre 1576 y 1579 . En esta fecha finalizaron las obras de cantería y albañilería de los aposentos de su majestad. El 17 de octubre de 1578, el carpintero Juan de la Laguna construyó una grúa para el patio mayor del aposento del Rey, por la que recibió cincuenta ducados en reales ${ }^{26}$.

Una práctica común, entre los ebanistas y carpìnteros del Monasterio, fue la de formar compañía para la adjudicación y realización de los destajos. Juan de la Laguna formó compañía en varias ocasiones con otro carpintero, como así se hace constar en un documento con fecha de 29 de septiembre de 1581:

«Juan de la Laguna y Julián Martínez [maestro de carpintería y vecino de la Puebla de Don Fadrique] hacen la escritura de compañía para todas las obras que tomen en el Monasterio de San Lorenzo de El Escorial, a partes iguales en pérdidas y ganancias ${ }^{27}$.

La rivalidad existente, en algunas ocasiones, entre las distintas compañías de carpinteros, para la adjudicación de las obras, es un hecho probado. El 8 de febrero de 1578 Juan de la Laguna y Andrés de León formaron compañía, en un primer momento, para hacer cuatro grúas en la iglesia principal del Monasterio (dos grúas para el antepecho del coro y las otras dos junto a las gradas del altar mayor),

\footnotetext{
${ }^{23}$ A.B.S.L.E., VI-2-1577; VI-9-1577.

24 Ídem.

${ }^{25}$ A.B.S.L.E., VI-21-1578.

26 Ídem.

${ }^{27}$ A.B.S.L.E., VII-35-1581. La actividad profesional de Juan de la Laguna y Julián Martínez, no se limitó exclusivamente a la construcción de grúas. También hicieron maderamientos y tijeras para distintas dependencias del Monasterio.
} 
todo ello por la cantidad de trescientos setenta y seis ducados en reales ${ }^{28}$. El 11 de febrero el carpintero Juan de Betesolo (también llamado en los documentos Vetosolo, Butisolo y Gotisolo), fiado por Domingo de Aranguren, hizo una cantraoferta de las dichas grúas, bajando el precio en noventa y cuatro ducados. La congregación lo rechazó, señalando que la obra no se puede hacer por ese precio. Finalmente se quedaron con la obra Juan de la Laguna y Juan de Betesolo, formando compañía y contando con la aceptación de Andrés de León ${ }^{29}$. Cada grúa costó ochenta y cuatro ducados ${ }^{30}$. Unos días después, el 18 de febrero, Juan de la Laguna y Juan de Betisolo otorgaron nueva escritura de obligación de las cuatro grúas citadas para la iglesia principal, por cuarenta ducados menos ${ }^{31}$. La compañía formada por estos dos maestros de carpintería dio nuevamente sus frutos cuando, el 23 de mayo de 1578, firmaron el concierto de los andamios para los cuatro arcos torales del crucero conforme a la planta y montea que se dio de ellos. Los citados carpinteros cobraron por esta obra cuatro mil novecientos reales ${ }^{32}$.

También intervinieron otros carpinteros en la construcción de grúas. En 1577, los carpinteros Pedro de Ragama o Rugamo (tal y como aparece en los documentos) y Juan de Aguirre hicieron dos grúas que, Simón Sánchez y Gregorio de la Puente, canteros, tenían en la iglesia principal. El 18 de enero de 1578 se les terminó de pagar percibiendo dos mil ochocientos cuarenta y ocho reales. Fray Antonio de Villacastín dio la obra por buena y la escritura por cumplida ${ }^{33}$.

A principios de 1579 surgió un problema en la construcción de las grúas, pues la altura de los muros era considerable y requirió elevar la altura de las mismas. Nadie se atrevió y tuvo que ser uno de los destajeros quien resolvió el problema, dando la traza y haciendo las grúas como él dice, claramente, en un memorial que envió al secretario Gaztelu el 11 de enero de 1579. Su nombre es Juan de Betesolo y lo explica así:

«Juan de Betesolo dice que fuéle mandado y llamado para hacer y dar traza de cierta[s] grúas que se habían de hacer y no se atrevió ningún maestro de los que en el dicho sitio estaban a hacer las dichas obras, como era razón para el servicio de Vra. Magestad. Pareciendo a ellos no ser suficientes para edificar las dichas grúas, trajeron al que aquí diese industria para hacerlas...»

A continuación detalla como hizo dos grúas grandes principalmente y cómo ahorró mucho material en madera y clavazón respecto a los otros aparatos. Suplica

\footnotetext{
${ }^{28}$ A.B.S.L.E., VI-23, folio 50v-51v-1578.

${ }^{29}$ A.B.S.L.E., VI-19-1578. A.G.P. San Lorenzo. Leg. 1793. Libro de la Congregación, folio 38v-39.

30 Ídem.

${ }^{31}$ A.B.S.L.E., VI-23-1578, folio 57-58 v; VI-15-1578.

32 Ibídem; ABSLE, VI-23-1578, folio 102v-105; VI-15-1578.

${ }^{33}$ A.B.S.L.E., VI-2-1577; VI-15-1578.
} 
una merced para ayuda en su actual enfermedad, etc. Corroborando la veracidad de lo expresado por Betesolo, el secretario escribe en el mismo documento:

«El dicho Juan de Betesolo vino a esta fábrica y tomó al principio de hacer dos grúas y para poner el pescante y sopapo y subir el mástil hizo una cabrilla grande, con que los hizo y acabó muy bien y después acá, con la dicha cabrilla y otra como ella, se han hecho otras grúas y se harán de aquí [en] adelante. Que en cada una de las hechas y que se hicieren se ha ahorrado mucha clavazón y madera y manos, con que la fábrica ha ganado y ganará mucho dinero...»

(Solicita en consecuencia se le haga merced pues es cierto que ahora está enfermo $)^{34}$. Este interesante documento, del Archivo General de Simancas, aclara la cuestión de la autoría de las grandes grúas que se emplearon en el Monasterio. Indica que ninguno de los maestros se atrevió a hacerlas, afirmación demasiado audaz si no fuese cierta. En el documento se especifica cómo se montaron con ayuda de una cabrilla grande, hecha por el mismo Betesolo y cómo las grúas sirvieron de modelo para hacer el resto de las empleadas en las obras. No existe, hasta la fecha, ningún dato biográfico de Betesolo. Lo único que se sabe es que era maestro carpintero, de origen vasco, que trabajaba en el Monasterio de San Lorenzo el Real en compañía de Juan de la Laguna, con el que hizo varios trabajos para la iglesia de San Lorenzo de El Escorial. En enero y febrero de 1578 recibió pagos por una grúa para las partidas que los maestros de cantería Gregorio de la Puente y Francisco de Atuy, tenían en la iglesia principal ${ }^{35}$. También intervino en el mismo destajo, unos meses después, el carpintero Pedro Miranda haciendo una grúa por la que cobró cuarenta ducados en reales ${ }^{36}$. El 21 de febrero de 1578, se libraron 336 ducados a Juan Betesolo y a su compañero «... por cuatro grúas de madera grandes que hicieron a destajo de toda costa de manos en la obra de la iglesia principal del dicho monasterio...» Además de ello, deshicieron una grúa que estaba en la obra de uno de los patios pequeños de dicha iglesia y la volvieron a hacer con algunas mejoras ${ }^{37}$. Poco tiempo después esto es corroborado por fray Antonio de Villacastín, indicando que los «dejaron por bien acabados y la obligación cumplida»38. El 11 de noviembre de 1578 Juan de la Laguna recibió cuarenta ducados en reales por una grúa que levantó en la partida de Juan de la Puente y Lope de Arredondo ${ }^{39}$.

Además de la labor de Diego de Valmaseda, Juan de la Laguna, Pedro de Ragama, Juan de Aguirre, Juan de Betesolo, Pedro Valgado y Pedro Miranda en lo

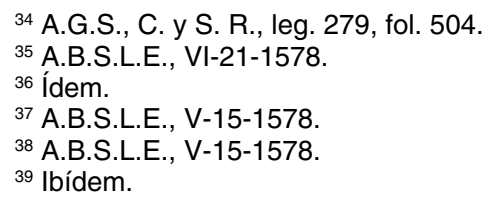


que a la construcción de grúas se refiere, igualmente hay que destacar la colaboración de un tal Juan Roxo (Rojo) y Pedro Flores en la fabricación de algunas piezas que componen las grúas (roldanas o garruchas, más conocidas como poleas $)^{40}$. La información de estos carpinteros es inexistente.

En el año 1578 el número de grúas y su altura era considerable; lo cuenta así fray José de Sigüenza:

«Había en solo la iglesia, veinte grúas de á dos ruedas, unas altas, otras bajas, y otras sobre éstas más altas, y sobre éstas tabladas y andamios que subian al cielo: estos daban voces a aquellos, los de abajo llamaban á los altos, los del medio á los unos y á los otros; de dia, de noche, á la tarde, a la mañana, no se oia si no: guinda, amaina, vuelve, revuelve, torna, estira, para tente, menea; bullia todo y crecia con aumento espantoso; parecia trabajaban no solo para dar de comer, como en otras obras, sino para dar remate y perfeccion á lo que tenian entre manos, en una amigable contencion y porfía, pretendiendo cada uno ir el primero, y junto con esto, ayudar al otro " ${ }^{41}$.

«La multitud de carretería, carreteras y bueyes, era también de consideración, por la puntualidad en que acudían á sus horas concertadas, proveyendo á las grúas de todo cuanto necesitaban... ${ }^{42}$.

Se deduce de este testimonio que el Monasterio de San Lorenzo de El Escorial era la imagen de una moderna obra de construcción, activa y altamente mecanizada en relación a su época, lo que permitió que se terminase en un período de tiempo asombrosamente corto en relación al volumen de la obra.

Esta magna obra atrajo a muchos inventores. El 21 de septiembre de 1579, se presentó en la obra Tomás de Capirola, italiano, pidiendo que se vea un modelo de máquina para llevar tierra de una parte a otra y levantarla en alto; llegó a mostrársela a Herrera, pero al parecer no llegó a aplicarse a la obra de San Lorenzo el Real ${ }^{43}$, lo cual es coherente con lo que el mismo Herrera dice en una memoria que envió a Mateo Vázquez con sus méritos, sobre el «haber desengañado de muchas máquinas, que algunas personas no fundadas en ellos han traído a estos rei-

${ }^{40} \mathrm{El} 8$ de agosto de 1577, se le pagaron doscientos veintiocho reales a Juan Rojo por haber hecho a destajo 38 roldanas de madera de encina para grúas (A.B.S.L.E., VI-2-1577). La dureza y resistencia de la madera de encina fue muy utilizada para la fabricación de poleas. El 20 de febrero de 1580, se le pagaron cien reales a Pedro Flores por haber labrado y guarnecido de hierro 16 roldanas para las grúas de la Real Fábrica (A.B.S.L.E., VII-15-1580).

${ }^{41}$ SIGÜENZA, fray José de., Historia primitiva y exacta del Monasterio de San Lorenzo de El Escorial. Madrid, Imprenta y Fundición de M. Tello (Impresor de cámara de S. M.), 1881. Libro I. D. XI, págs. 124-125.

42 Ibídem, pág. 127.

${ }^{43}$ A.G.S., C. y S. R., leg. 280 , fols. 42 y 43. 
nos...»44. En la década de los 80 la iglesia principal seguía acaparando mucha actividad. El 15 de enero de 1580 Juan de la Laguna recibió pagos por dos grúas para las torres de la iglesia principal ${ }^{45}$. En este mismo año formó compañía con Juan Ramos y firmaron las condiciones para hacer ocho grúas y desarmar los andamios y cámaras de las mismas, tal y como aparece en el documento ${ }^{46}$. La actividad de Juan de la Laguna en la iglesia principal fue intensa en estos primeros años de la década de los 80 . Para esta zona del Monasterio hizo una serie de trabajos que detallo a continuación: el 6 de febrero se obligó a hacer dos grúas para el pórtico principa ${ }^{47}$; en marzo quitó un mástil quebrado de una grúa de la fábrica e hizo otro nuevo ${ }^{48}$; el 15 de abril de 1581 se obligó a subir de altura la grúa que los canteros Juan de la Puente y Lope de Redondo, tenían en la torre principal conforme a la de Diego de Cisniega; también se obligó a hacer dos grúas para el pórtico y por desarmar otras dos; hizo un tiro y una cámara en la torre de Diego de Cisniega; desarmó una grúa vieja más cuatro grúas para cerrar la media naranja, $y$ tres andamios en la torre de las campanas ${ }^{49}$.

La labor en las torres de la iglesia principal continuó en 1581. El 2 de septiembre Juan de la Laguna recibió pagos por dos andamios, 24 cimbras de madera y los suelos de grúas que hizo a destajo en las torres y cúpula de la iglesia principal ${ }^{50}$. Además se le libraron veinte ducados en reales por añadir los pescantes de cuatro grúas en la cúpula de la iglesia principal ${ }^{51}$. En 1582, entre otros trabajos, desarmó dos grúas de la cúpula ${ }^{52}$. El 12 de julio de 1582 firmó las condiciones para desarmar las cimbras y las doce grúas de la cúpula ${ }^{53}$. El 27 de mayo de 1583, el carpintero Juan Ramos se encargó de desarmar dos grúas y todos los andamios de la torre de la partida de Juan de la Puente, recibiendo doscientos ducados en reales ${ }^{54}$.

De las cuatro torres del Monasterio, la de la botica fue la más accidentada. En 1585 se trazó la nueva botica, cuyas obras de cantería se obligaron a hacer Bartolomé de Elorriaga, Pedro del Carpio y Alonso de Torres. El 2 de junio de 1590, el carpintero Julián Martínez recibió doce ducados por una grúa que desarmó para el cuarto de la botica ${ }^{55}$.

${ }^{44}$ CEÁN BERMÚDEZ, J. A., y LLAGUNO Y AMIROLA, E., Noticias de los arquitectos y arquitectura de España desde su restauración. Madrid, Imprenta Real, 1829, apéndice XXII, 10, págs. 332 y ss.

${ }^{45}$ A.B.S.L.E., VII-15-1580.

${ }^{46}$ A.B.S.L.E., VII-26-1580; VII-16-1580.

${ }^{47}$ A.B.S.L.E., VII-15-1580.

48 Ídem.

${ }^{49}$ A.B.S.L.E., VII-34-1581; VII-36-1581.

${ }^{50}$ A.B.S.L.E., VII-36-1581.

51 Ídem.

52 A.B.S.L.E., VIII-3-1582

${ }^{53}$ A.B.S.L.E., VII-14-1582; VIII-1-1582, folio 9-10 (condiciones). A.B.S.L.E., VIII-9-1582 (libranzas).

${ }^{54}$ A.B.S.L.E., VIII-24-1583.

${ }^{55}$ A.B.S.L.E., XI-45-1590. 
Quedaba finalmente las estatuas de los Reyes del Antiguo Testamento en la fachada de la iglesia, realizada por el aparejador Juan de Minjares, por medio de unos polipastos volados y sujetos a la propia fachada, que llevaron las estatuas con ayuda de unos contrapesos; se trata de un sistema diferente al de las grúas apoyadas por una estructura en el suelo, lo que en este caso no es ya necesario al estar construida la iglesia. La operación tuvo lugar entre el 30 de julio y el 3 de agosto de 1584, según los testimonios de fray Juan de San Jerónimo y fray José de Sigüenza ${ }^{56}$. Sin embargo el propio Juan de Minjares —o Mijares como el mismo afirma- debió de sufrir un despiste de fechas, cuando dice que lo hizo entre los años 1585 y 1586, en una autógrafa dirigida al secretario del Rey y fechada el 1 de mayo de 1590:

«Viernes a cuatro de mayo de mil e quinientos y ochenta y cinco años, partí de Sevilla por orden de Su Magd. Para ir a San Lorenzo el Real, a subir los Reyes que están puestos en el pórtico de la iglesia y me ocupé en esto y en hacer tasaciones y otras cosas, hasta [el] lunes diez y ocho de marzo del año siguiente de ochenta y seis, que volví a Sevilla sin haberme ocupado en otra cosa... ${ }^{57}$.

Minjares o Mijares, era un excelente y consumado especialista en este tipo de operaciones, pues ya en las obras de Aranjuez y concretamente en la presa de Ontígola había demostrado su habilidad en la fabricación de unas grúas ${ }^{58}$. Aunque considerados de segunda fila, por el tipo de trabajo que desempeñaron en la Real Fábrica, su contribución a la elevación de los muros y en el sistema de cubrición del Monasterio fue determinante.

Se desconoce lo que se hizo con todas las grúas de la obra escurialense una vez desmontadas. Posiblemente el material fuese reutilizado en otro menester. Lo cierto es que años después no estaban ya en el Monasterio pues, en 1593, la iglesia de Valdemorillo (municipio próximo a San Lorenzo de El Escorial) pedía como merced una grúa de la Real Fábrica escurialense, contestando fray Antonio de Villacastín que, según fray Diego de Yepes ${ }^{59}$, no existía tal grúa ${ }^{60}$.

En 1588 Juan de Herrera dio las trazas para las dos casas de oficios, situadas enfrente del Monasterio. El 2 de junio el carpintero Julián Martínez recibió veinticuatro ducados por desmontar dos grúas ${ }^{61}$.

56 ÍNIIGUEZ ALMECH, Fr., Op. cit., pág. 199.

${ }^{57}$ A.G.S., C. y S. R., leg. 270, fol. 101.

58 Ídem., leg. 273, fol. 114. ta 1594 .

59 Diego de Yepes sustituyó a fray Juan de San Jerónimo en 1591, ocupando el puesto de prior has-

${ }^{60}$ A.G.S., C. y S. R.. leg. 302, fol. 33.

${ }^{61}$ A.B.S.L.E., XI-45-1590. 
Si bien es cierto que las grúas del Monasterio no representaron en sí mismas ninguna innovación tecnológica, también lo es el hecho que fuesen extraordinariamente grandes y su construcción requiriese, más que de la inteligencia y de los conocimientos matemáticos de un arquitecto, de la audacia y habilidad de un especialista en estructuras de madera. Fue en ese preciso momento cuando la figura del carpintero se vio especialmente reforzada, para solucionar los complejos problemas de las estructuras de los andamios y de las grúas.

La imagen de una moderna obra de construcción, activa y altamente mecanizada en relación a su época, fue lo que se permitió que se terminase en un periodo de tiempo asombrosamente corto en relación al volumen de la obra. 